\title{
PREVALENCE OF METABOLIC SYNDROME IN VERY LOW BIRTH WEIGHT INFANTS AT 2 YEARS OF AGE
}

\author{
R.C. Silveira, L.A. Heidemann, A.C. Terrazan, R.S. Procianoy \\ Universidade Federal do Rio Grande do Sul/Hospital de Clinicas de Porto Alegre, Porto Alegre, Brazil
}

Background: There is no study showing the prevalence of MS in preterm in early childhood.

Objective: To assess the prevalence of MS in children with birthweight $<1500$ grams at two years of age and identify perinatal or early childhood factors associated with occurrence of MS.

Design/methods: A cross sectional study with two years of age children that attended a preterm follow up clinic. Criteria for MS diagnosis were three or more of: waist circumference $\geq 90$ th percentile, fasting glucose $\geq 100 \mathrm{mg} / \mathrm{dl}$, triglycerides $\geq 110 \mathrm{mg} / \mathrm{dL}$, HDL cholesterol $\geq 40 \mathrm{mg} / \mathrm{dl}$ and blood pressure $\geq 90$ th percentile.

Results: 235 preterm children with very low birth weight were discharged to outpatient care. Of these, 9.4\% failed the follow up. Of the 212 evaluated children, 32(15.1\%) had MS. Maternal preeclampsia, gestational diabetes, sex, gestational age, SGA, early and late sepsis, BPD, TPN in the first 24 hours of life, NEC, IVH and PVL, PDA, diet at discharge and during the first year of life, income and maternal education were similar between groups. Maternal urinary tract infection or chorioamnionitis showed a higher prevalence of MS $(p=0.032)$. Neonatal meningitis presented more MS $(p=0.003)$. Using Poisson regression, the history of meningitis was the only variable related to the presence of MS $(p=0.06)$.

Conclusions: MS is already present in very low birth weight preterm at 2 years. Maternal peripartum infection probably leads to an increase in fetal cortisol, programming MS. Severity of infection, such as neonatal meningitis, appears to be an additional risk factor. 